\title{
Adaptabilidade e estabilidade de cultivares de milho no Nordeste brasileiro no triênio 1998 a $2000^{(1)}$
}

\author{
Hélio Wilson Lemos de Carvalho(2), Maria de Lourdes da Silva Leal(2), Milton José Cardoso(3), \\ Manoel Xavier dos Santos ${ }^{(4)}$, José Nildo Tabosa ${ }^{(5)}$, Benedito Carlos Lemos de Carvalho ${ }^{(6)}$ e Marcelo Abdon Lira(7)
}

\begin{abstract}
Resumo - Foram avaliadas 22 cultivares de milho (variedades, híbridos e populações) em 45 ambientes do Nordeste brasileiro, no triênio 1998 a 2000, objetivando conhecer a adaptabilidade e a estabilidade desses materiais para fins de recomendação. Utilizou-se delineamento experimental em blocos ao acaso com três repetições. A análise de variância conjunta mostrou inconsistência no comportamento das cultivares diante das variações ambientais. Os híbridos mostraram melhor adaptação que as variedades e populações, constituindo-se em alternativas viáveis para os produtores que investem em tecnologias modernas de produção; sobressaíram-se Cargill 333 B, AG 1051 e Zeneca 8501. As variedades Sertanejo, AL 25, São Francisco, São Vicente, Asa Branca e BR 106 são importantes nos sistemas de produção dos pequenos e médios produtores rurais da região.
\end{abstract}

Termos para indexação: Zea mays, híbrido, variedade, interação genótipo x ambiente.

\section{Adaptability and stability of maize cultivars in the Brazilian Northeast region from 1998 to 2000}

\begin{abstract}
During the years 1998 to 2000, 22 maize cultivars (varieties, hybrids and populations) were evaluated in 45 environments of the Brazilian Northeast region, in order to know the adaptability and the stability of those materials for recommendation purposes. The experimental design was random blocks with three repetitions. The combined analysis of variance showed inconsistency in the behavior for the cultivars due to environmental variations. The hybrids showed better adaptation than the varieties and populations, especially Cargill $333 \mathrm{~B}$, AG 1051 and Zeneca 8501, which are viable alternatives for farmers that invest in modern technologies. The varieties Sertanejo, AL 25, São Francisco, São Vicente, Asa Branca and BR 106 are indicated to the farming systems of the small and medium farmers.
\end{abstract}

Index terms: Zea mays, hybrid, variety, genotype $\mathrm{x}$ environment interaction.

(1)Aceito para publicação em 15 de abril de 2002.

(2) Embrapa-Centro de Pesquisa Agropecuária dos Tabuleiros Costeiros, Caixa Postal 44, CEP 49001-970 Aracaju, SE. E-mail: helio@cpatc.embrapa.br, lurdinha@cpatc.embrapa.br

(3) Embrapa-Centro de Pesquisa Agropecuária do Meio-Norte, Caixa Postal 01, CEP 64066-220 Teresina, PI. E-mail: milton@cpamn.embrapa.br

(4) Embrapa-Centro Nacional de Pesquisa de Milho e Sorgo, Caixa Postal 151, CEP 35701-970 Sete Lagoas, MG. E-mail: xavier@cnpms.embrapa.br

(5) Empresa Pernambucana de Pesquisa Agropecuária, Caixa Postal 1022, CEP 50761-000 Recife, PE. E-mail: tabosa@ipa.br

(6) Empresa Baiana de Desenvolvimento Agrícola, Av Dorival Caymmi, 15649, Salvador, BA. E-mail: ebdadexp@ebda.ba.gov.br

(7) Empresa de Pesquisa Agropecuária do Rio Grande do Norte, Caixa Postal 188, CEP 59020-390 Natal, RN. E-mail: marcelo@dmrh.emparn.br

\section{Introdução}

No Nordeste brasileiro predominam inúmeros sistemas de produção de milho, desde aqueles onde é quase ausente a aplicação de tecnologias de produção até aqueles onde se procura explorar todo o potencial da cultura mediante a utilização de tecnologias modernas de produção. A produtividade do milho oscila de $800 \mathrm{~kg} / \mathrm{ha}$ nos sistemas de plantios tradicionais, onde se verificam consórcios com o feijão e o algodão, até mais de $6.500 \mathrm{~kg} / \mathrm{ha}$, em plantios tecnificados, comuns nos cerrados baianos, no Sul do Maranhão e no pólo Uruçuí-Gurgéia, no Estado do Piauí. Esses níveis elevados de produtividade têm sido constatados também em trabalhos de competição de cultivares realizados nos Municípios de Parnaíba (Cardoso et al., 1997) e Teresina, no Piauí, 
em Missão Velha e Limoeiro do Norte, no Ceará, e Ipanguassu, no Rio Grande do Norte (Carvalho et al., 1998), nos Municípios de Brejo Santo e Porteiras, no Ceará (Carvalho et al., 1999a) e nos Municípios de Floriano, Teresina e Parnaíba, no Piauí (Cardoso et al., 2000).

Distintas condições ambientais existem no Nordeste brasileiro (Silva et al., 1993), e o milho, com algumas restrições, é cultivado em todas elas. Considerando este aspecto e aquele relacionado aos diferentes sistemas de produção prevalecentes na região infere-se que é de interesse o desenvolvimento de um programa de avaliação de variedades e híbridos, visando subsidiar os agricultores na escolha de cultivares de melhor adaptação e que sejam portadoras de atributos agronômicos desejáveis. Todavia, segundo Ribeiro et al. (2000), um dos grandes problemas é quando as cultivares são postas a competir em vários ambientes. Neste caso, a classificação relativa entre elas pode não ser coincidente com a da pesquisa, o que dificulta a identificação daquelas efetivamente superiores. Esse efeito é minimizado mediante a seleção de genótipos com maior estabilidade fenotípica (Ramalho et al., 1993).

Diversos trabalhos ressaltam a importância e a influência da interação cultivar $\mathrm{x}$ ambiente, principalmente nas fases do programa que envolvem a avaliação final e a recomendação de cultivares (Ruschel, 1968; Lemos, 1976; Naspolini Filho, 1976; Arias, 1995; Carneiro, 1998; Gama et al., 2000; Ribeiro et al., 2000).

O objetivo deste trabalho foi verificar a adaptabilidade e a estabilidade de diferentes cultivares de milho, quando submetidas a distintas condições ambientais do Nordeste brasileiro.

\section{Material e Métodos}

Foram realizados 45 ensaios, distribuídos nos anos agrícolas de 1998 (15 ensaios), 1999 (13 ensaios) e 2000 (17 ensaios). Utilizou-se o delineamento experimental em blocos ao acaso, com três repetições e 22 tratamentos (sete híbridos, oito variedades, cinco populações e dois sintéticos). Cada parcela constou de quatro fileiras de $5,0 \mathrm{~m}$ de comprimento, espaçadas de $0,90 \mathrm{~m}$ e com $0,50 \mathrm{~m}$ entre covas. Foram semeadas três sementes, deixando-se duas plantas por cova após o desbaste. Foram colhidas as duas fileiras centrais de modo integral, resultando numa área útil de $9,0 \mathrm{~m}^{2}$. As adubações foram realizadas conforme os resultados das análises de solo de cada área experimental.

As coordenadas geográficas de cada município e os tipos de solo das áreas experimentais são apresentados na Tabela 1.

Os pesos de grãos (15\% de umidade) foram submetidos à análise de variância pelo modelo de blocos ao acaso. A análise de variância conjunta obedeceu ao critério de homogeneidade dos quadrados médios residuais (PimentelGomes, 1985). As referidas análises foram efetuadas utilizando-se o Statistical Analysis System (SAS Institute, 1996) para dados balanceados (PROC ANOVA).

Para atenuar o efeito da interação cultivar $\mathrm{x}$ ambiente, usou-se o método de Cruz et al. (1989), que baseia-se na análise de regressão bissegmentada, tendo como parâmetros de adaptabilidade a média $\left(\mathrm{b}_{0}\right)$, a resposta linear aos ambientes desfavoráveis $\left(b_{1}\right)$ e aos ambientes favoráveis $\left(b_{1}+b_{2}\right)$. A estabilidade das cultivares foi avaliada pelos desvios da regressão $\sigma^{2}{ }_{\mathrm{ij}}$ de cada material, de acordo com as variações ambientais.

Foi utilizado o seguinte modelo:

$Y_{i j}=b_{0 i}+b_{1 i} I_{j}+b_{2 i} T(I)+\delta i j+e_{i j}$ onde:

$\mathrm{Y}_{\mathrm{ij}}$ : média da cultivar i no ambiente $\mathrm{j}$; $\mathrm{I}_{\mathrm{j}}$ : índice ambiental; $\mathrm{T}\left(\mathrm{I}_{\mathrm{j}}\right)=0$ se $\mathrm{I}_{\mathrm{j}}<0 ; \mathrm{T}\left(\mathrm{I}_{\mathrm{j}}\right)=\mathrm{Ii}_{\mathrm{j}}-\overline{\mathrm{I}}_{+}$se $\mathrm{Ij}>0$, sendo $\overline{\mathrm{I}}_{+}$a média dos índices $\mathrm{I}_{\mathrm{j}}$ positivos; $\mathrm{b}_{0 \mathrm{i}}$ : média geral da cultivar $\mathrm{i}$; $\mathrm{b}_{1 \mathrm{i}}$ : coeficiente de regressão linear associado a ambientes desfavoráveis; $b_{1 i}+b_{2 i}$ : coeficiente de regressão linear associado a ambientes favoráveis; $\delta_{\mathrm{ij}}$ : desvio da regressão linear; $\mathrm{e}_{\mathrm{ij}}$ : erro médio associado à média.

\section{Resultados e Discussão}

Em relação ao peso de grãos, houve diferenças significativas a $1 \%$ de probabilidade, pelo teste $\mathrm{F}, \mathrm{o}$ que indica comportamento diferenciado entre os materiais avaliados, dentro de cada local (Tabela 2). Os coeficientes de variação oscilaram de 7,0\% a $20,3 \%$, conferindo boa precisão aos experimentos (Scapim et al., 1995). A média de rendimento de grãos nos ensaios variou de $3.262 \mathrm{~kg} / \mathrm{ha}$, em Adustina 2, na Bahia, no ano agrícola de 1998, a $8.323 \mathrm{~kg} / \mathrm{ha}$, em Parnaíba (ambiente irrigado), no Piauí, no ano agrícola de 2000, o que revela uma ampla faixa de variação nas condições ambientais em que foram realizados os ensaios. Parte dessa variação ocorreu provavelmente por causa das diferenças de solo (Tabela 1).

No ano agrícola de 1998, os Municípios de Floriano e Teresina (ambiente irrigado), Teresina (em 
solo aluvial), no Estado do Piauí, Adustina 1 e Barreiras, na Bahia, e Nossa Senhora das Dores e Neópolis, em Sergipe, mostraram produtividades médias superiores à média geral $(5.021 \mathrm{~kg} / \mathrm{ha}$ de grãos). No ano de 1999, os Municípios de Teresina (ambientes irrigado e sequeiro), Araripina, em Pernambuco, e Barreiras e Barra do Choça, na Bahia, também apresentaram rendimentos médios superiores à média geral. No ano 2000, as produtividades médias obtidas nos Municípios de Anapurus e Barra do Corda, no Maranhão, Parnaíba (ambientes irrigado e sequeiro), Teresina (ambiente irrigado) e Rio Grande do Piauí, no Piauí, Barreiras, Barra do Choça e Lapão, na Bahia, superaram também a média geral. Esses ambientes apresentaram melhores potencialidades para o desenvolvimento do milho, obtendo-se rendimentos médios de $5.079 \mathrm{~kg} / \mathrm{ha} \mathrm{a} 8.323 \mathrm{~kg} / \mathrm{ha}$ de grãos, destacando-se como os ambientes mais favoráveis aqueles com produtividades médias acima de $6.000 \mathrm{~kg} / \mathrm{ha}$ de grãos. Os rendimentos médios registrados nesses ambientes mais favoráveis coloca essas áreas em condições de competir com áreas dos Estados de Goiás e Mato Grosso, reduzindo os custos com a importação de milho de outras partes do país para complementar a necessidade regional.

Houve efeitos significativos $(\mathrm{P}<0,01)$ quanto aos ambientes, cultivares e interação cultivares $\mathrm{x}$ ambientes, o que evidencia o comportamento diferenciado entre as cultivares e o comportamento inconsistente das mesmas por causa das variações ambientais (Tabela 3). Interações significativas têm sido detectadas em trabalhos de competição de cultivares, conforme Carvalho et al. (1992, 1999b, 1999c, 2000a, 2000b), Arias (1995), Carneiro (1998) e Gama

Tabela 1. Coordenadas geográficas dos locais e tipos de solos das áreas experimentais.

\begin{tabular}{|c|c|c|c|c|}
\hline Município & Latitude (S) & Longitude (W) & Altitude (m) & Tipo de solo \\
\hline & \multicolumn{4}{|c|}{ Maranhão } \\
\hline Anapurus & $3^{\circ} 55^{\prime}$ & $43^{\circ} 30^{\prime}$ & - & Latossolo Vermelho-Amarelo \\
\hline \multirow[t]{2}{*}{ Barra do Corda } & $5^{\circ} 43^{\prime}$ & $45^{\circ} 18^{\prime}$ & - & Latossolo Vermelho-Amarelo \\
\hline & \multicolumn{4}{|c|}{ Piauí } \\
\hline Parnaíba & $2^{\circ} 63^{\prime}$ & $41^{\circ} 41^{\prime}$ & 15 & Neossolo Quartzarênico \\
\hline Teresina & $5^{\circ} 5^{\prime}$ & $42^{\circ} 49^{\prime}$ & 12 & Neossolo Flúvico \\
\hline Guadalupe & $6^{\circ} 26^{\prime}$ & $43^{\circ} 50^{\prime}$ & 180 & Latossolo Vermelho-Amarelo \\
\hline Angical do Piauí & $6^{\circ} 15^{\prime}$ & $42^{\circ} 51^{\prime}$ & 15 & Chernossolo \\
\hline Floriano & $6^{\circ} 46^{\prime}$ & $43^{\circ} 1^{\prime}$ & 85 & Neossolo Flúvico \\
\hline \multirow[t]{2}{*}{ Rio Grande } & $7^{\circ} 36^{\prime}$ & $43^{\circ} 31^{\prime}$ & 270 & Alissolo Vermelho-Amarelo \\
\hline & \multicolumn{4}{|c|}{ Rio Grande do Norte } \\
\hline \multirow[t]{2}{*}{ Ipangassu } & $5^{\circ} 37^{\prime}$ & $36^{\circ} 50^{\prime}$ & 70 & Alissolo Vermelho-Amarelo \\
\hline & \multicolumn{4}{|c|}{ Pernambuco } \\
\hline Araripina & $7^{\circ} 33^{\prime}$ & $40^{\circ} 34^{\prime}$ & 620 & Latossolo Vermelho-Amarelo \\
\hline São Bento do Una & $8^{\circ} 31^{\prime}$ & $36^{\circ} 22^{\prime}$ & 645 & Neossolo Rebolítico \\
\hline Caruaru & $8^{\circ} 34^{\prime}$ & $38^{\circ} 0^{\prime}$ & 537 & Alissolo Vermelho-Amarelo \\
\hline \multirow[t]{2}{*}{ Serra Talhada } & $8^{\circ} 17^{\prime}$ & $38^{\circ} 29^{\prime}$ & 365 & Alissolo Vermelho-Amarelo \\
\hline & \multicolumn{4}{|c|}{ Sergipe } \\
\hline Nossa Sra. das Dores & $10^{\circ} 30^{\prime}$ & $37^{\circ} 13^{\prime}$ & 200 & Latossolo Vermelho-Amarelo \\
\hline Umbaúba & $12^{\circ} 20^{\prime}$ & $37^{\circ} 40^{\prime}$ & 109 & Alissolo Vermelho-Amarelo \\
\hline \multirow[t]{2}{*}{ Neópolis } & $10^{\circ} 16^{\prime}$ & $36^{\circ} 5^{\prime}$ & 15 & Neossolo Flúvico \\
\hline & \multicolumn{4}{|c|}{ Bahia } \\
\hline Adustina 1 & $10^{\circ} 32^{\prime}$ & $38^{\circ} 7^{\prime}$ & 250 & Latossolo Vermelho-Amarelo \\
\hline Adustina 2 & $10^{\circ} 32^{\prime}$ & $38^{\circ} 7^{\prime}$ & 250 & Latossolo Vermelho-Amarelo \\
\hline Barreiras 1 & $12^{\circ} 9^{\prime}$ & $44^{\circ} 59^{\prime}$ & 800 & Neossolo Quartzarênico \\
\hline Barreiras 2 & $12^{\circ} 14^{\prime}$ & $45^{\circ} 20^{\prime}$ & 780 & Neossolo Quartzarênico \\
\hline Barreiras & $12^{\circ} 20^{\prime}$ & $44^{\circ} 10^{\prime}$ & 435 & Neossolo Flúvico \\
\hline Ibititá & $11^{\circ} 32^{\prime}$ & $41^{\circ} 41^{\prime}$ & 700 & Neossolo Flúvico \\
\hline Lapão & $11^{\circ} 21^{\prime}$ & $41^{\circ} 41^{\prime}$ & 785 & Neossolo Flúvico \\
\hline Barra do Choça & $14^{\circ} 51^{\prime}$ & $40^{\circ} 50^{\prime}$ & 900 & Alissolo Vermelho-Amarelo \\
\hline
\end{tabular}


Tabela 2. Resumo das análises de variância de rendimento de grãos ( $\mathrm{kg} / \mathrm{ha}$ ) de cada ensaio. Região Nordeste do Brasil, $1998 / 1999 / 2000^{(1)}$.

\begin{tabular}{|c|c|c|c|c|c|}
\hline \multirow[t]{2}{*}{ Local } & \multicolumn{3}{|c|}{ Quadrado médio } & \multirow[t]{2}{*}{ Média } & \multirow[t]{2}{*}{ CV (\%) } \\
\hline & Blocos & Cultivares & Resíduo & & \\
\hline & & & 1998 & & \\
\hline Angical do Piauí & $358.763,6$ & $2.479 .991,4^{* *}$ & $171.555,7$ & 4.160 & 10,0 \\
\hline Floriano & $6.086,4$ & $1.732 .988,2^{* *}$ & $186.594,3$ & 4.660 & 9,3 \\
\hline Floriano irrigado & $283.209,4$ & $1.209 .051,3^{* *}$ & $162.906,3$ & 5.420 & 7,0 \\
\hline Parnaíba & $17.798,0$ & $2.081 .475,3 * *$ & $155.180,2$ & 4.700 & 7,5 \\
\hline Parnaíba irrigado & $332.383,3$ & $591.517,4 * *$ & $156.215,1$ & 3.977 & 9,9 \\
\hline Teresina 'Aluvial' & $19.819,7$ & $3.810 .367,1^{* *}$ & $201.083,2$ & 5.628 & 8,0 \\
\hline Teresina 'Latossolo' & $426.115,1$ & $1.359 .871,6^{* *}$ & $150.213,3$ & 4.721 & 7,0 \\
\hline Teresina irrigado & $111.001,5$ & $1.625 .165,1 * *$ & $243.361,3$ & 5.943 & 8,3 \\
\hline Ipanguassu & $347.870,9$ & $1.249 .005,0^{* *}$ & $225.608,0$ & 4.228 & 11,2 \\
\hline Adustina 1 & $1.133 .295,4$ & $1.284 .184,7^{* *}$ & $220.716,1$ & 5.341 & 8,8 \\
\hline Adustina 2 & $582.262,8$ & $2.984 .379,5 * *$ & $441.638,3$ & 3.262 & 20,3 \\
\hline Barreiras & $1.018 .901,5$ & $2.187 .669,5^{* *}$ & $457.274,5$ & 5.079 & 16,6 \\
\hline N. Sra. das Dores & $246.218,4$ & $3.741 .289,2 * *$ & $371.410,4$ & 5.745 & 10,6 \\
\hline Neópolis & $410.112,9$ & $4.437 .521,6^{* *}$ & $283.248,9$ & 5.490 & 9,7 \\
\hline \multirow[t]{2}{*}{ Umbaúba } & $46.377,0$ & $2.227 .756,6^{* *}$ & $221.000,0$ & 3.694 & 12,7 \\
\hline & & & 1999 & & \\
\hline Floriano & $219.109,1$ & $2.162 .984,1 * *$ & $207.897,0$ & 4.110 & 11,1 \\
\hline Guadalupe & $31.610,6$ & $1.933 .154,7^{* *}$ & $136.813,8$ & 3.765 & 9,4 \\
\hline Parnaíba irrigado & $487.110,6$ & $2.712 .208,0^{* *}$ & $373.997,8$ & 4.941 & 12,4 \\
\hline Parnaíba & $206.866,2$ & $2.428 .870,9^{* *}$ & $291.397,2$ & 4.717 & 11,4 \\
\hline Rio Grande & $205.910,6$ & $1.983 .145,0^{* *}$ & $226.720,1$ & 3.982 & 12,0 \\
\hline Teresina irrigado & $1.021 .586,4$ & $1.927 .973,7^{* *}$ & $206.969,3$ & 5.380 & 8,4 \\
\hline Teresina & $66.624,2$ & $3.459 .338,1 * *$ & $175.778,2$ & 5.821 & 7,2 \\
\hline Araripina & $323.020,3$ & $3.067 .426,8^{* *}$ & $296.642,4$ & 5.079 & 10,7 \\
\hline N. Sra. das Dores & $987.463,8$ & $3.117 .133,6^{* *}$ & $277.329,3$ & 4.955 & 10,6 \\
\hline Neópolis & $68.061,7$ & $7.274 .273,4 * *$ & $228.891,6$ & 4.513 & 10,6 \\
\hline Barreiras & $1.144 .287,0$ & $7.897 .196,4 * *$ & $475.689,6$ & 5.171 & 13,3 \\
\hline Barra do Choça & $2.578 .259,1$ & $3.402 .731,7 * *$ & $688.461,0$ & 5.087 & 16,3 \\
\hline \multirow[t]{2}{*}{ Lapão } & $396.749,8$ & $1.646 .498,7^{* *}$ & $399.457,6$ & 3.323 & 19,0 \\
\hline & & & 2000 & & \\
\hline Anapurus & $2.155 .429,3$ & $3.974 .641,1 * *$ & $612.517,0$ & 5.960 & 13,1 \\
\hline Barra do Corda & $2.542 .228,5$ & $1.634 .428,0^{* *}$ & $316.047,2$ & 5.179 & 10,9 \\
\hline Guadalupe & $433.782,0$ & $1.178 .188,9^{* *}$ & $322.618,6$ & 4.446 & 12,8 \\
\hline Parnaíba & $1.016 .343,0$ & $3.081 .004,6^{* *}$ & $298.131,2$ & 6.522 & 8,4 \\
\hline Parnaíba irrigado & $593.745,9$ & $4.312 .535,0 * *$ & $444.385,3$ & 8.323 & 8,0 \\
\hline Teresina irrigado & $205.040,9$ & $6.657 .498,3^{* *}$ & $384.795,6$ & 6.869 & 9,0 \\
\hline Rio Grande & $1.317 .926,4$ & $2.728 .238,1^{* *}$ & $377.984,5$ & 6.699 & 9,2 \\
\hline Araripina & $259.643,4$ & $2.892 .119,3^{* *}$ & $407.170,5$ & 4.991 & 12,8 \\
\hline Caruaru & $635.719,7$ & $3.611 .724,4 * *$ & $218.180,0$ & 4.676 & 9,9 \\
\hline São Bento do Una & $667.704,4$ & $2.431 .737,6^{* *}$ & $167.573,8$ & 3.696 & 11,1 \\
\hline Serra Talhada & $918.728,7$ & $977.084,4^{* *}$ & $214.537,5$ & 3.802 & 12,1 \\
\hline Barreiras 1 & $39.664,4$ & $5.630 .707,4^{* *}$ & $446.445,6$ & 6.119 & 10,9 \\
\hline Barreiras 2 & $38.120,2$ & $7.858 .987,5^{* *}$ & $386.422,8$ & 5.159 & 12,0 \\
\hline Barra do Choça & $3.575 .451,7$ & $4.550 .454,7^{* *}$ & $332.116,2$ & 5.441 & 10,6 \\
\hline Ibititá & $1.194 .475,9$ & $2.176 .660,6^{* *}$ & $439.821,2$ & 5.004 & 13,2 \\
\hline Lapão & $357.788,0$ & $4.520 .815,5^{* *}$ & $538.293,7$ & 6.387 & 11,4 \\
\hline N. Sra. das Dores & $45.088,3$ & $4.853 .526,6^{* *}$ & $163.287,0$ & 4.775 & 7,9 \\
\hline
\end{tabular}

${ }^{(1)}$ Graus de liberdade: 2 (blocos), 21 (cultivares) e 42 (resíduos). ${ }^{*}$ Significativo a $1 \%$ de probabilidade pelo teste $\mathrm{F}$. 
et al. (2000). Em todos esses casos os autores procuraram minimizar o efeito dessa interação por meio da recomendação de cultivares de melhor estabilidade fenotípica.

Detectada a presença da interação cultivares $\mathrm{x}$ ambientes, procurou-se verificar as respostas de cada uma delas nos ambientes considerados. Pelo método proposto, busca-se como cultivar ideal aquela que apresenta alta produtividade média, adaptabilidade nos ambientes desfavoráveis $\left(\mathrm{b}_{1}\right.$ o menor possível), capacidade de responder à melhoria ambiental $\left(b_{1}+b_{2}\right.$ o maior possível $) e$, finalmente, variância dos desvios de regressão igual a zero.

Além do preconizado pelo método de Cruz et al. (1989), considerou-se como cultivar melhor adaptada aquela que expressou rendimento médio superior à média geral (Mariotti et al., 1976). Os rendimentos médios de grãos $\left(\mathrm{b}_{0}\right)$ oscilaram de $3.505 \mathrm{~kg} / \mathrm{ha}$ (CMS 47) a $6.489 \mathrm{~kg} /$ ha (Cargill 333 B), com média geral de $5.021 \mathrm{~kg} / \mathrm{ha}$, o que revela o bom desempenho produtivo das cultivares avaliadas no Nordeste brasileiro (Tabela 4). As cultivares de rendimentos superiores à média geral mostraram melhor adaptação, destacando-se entre elas os híbridos Zeneca 8501, AG 1051 e Cargill 333 B, com rendimentos de grãos de $6.061 \mathrm{~kg} / \mathrm{ha} \mathrm{a} 6.409 \mathrm{~kg} / \mathrm{ha}$. Os híbridos apresentaram melhor adaptação que as variedades, populações e sintéticos, produzindo, em média, $5.918 \mathrm{~kg} /$ ha de grãos, superando em $30 \%$ o rendimento médio das variedades, populações e sintéti$\cos (4.583 \mathrm{~kg} /$ ha de grãos$)$.

Ao analisar o comportamento dos materiais de melhor adaptação (produtividades médias superiores à média geral), a estimativa de $b_{1}$, que avalia os desempenhos nas condições desfavoráveis, revelou que os híbridos Cargill 333 B, AG 1051 e Zeneca 8501 mostraram ser muito exigentes nessas

Tabela 3. Análise de variância conjunta de rendimento de grãos (kg/ha) de 22 cultivares de milho em 45 ambientes do Nordeste brasileiro, no triênio 1998/1999/2000.

\begin{tabular}{lcc}
\hline Fonte de variação & Graus de liberdade & Quadrados médios \\
\hline Ambientes (A) & 44 & $68.430 .296,5^{* *}$ \\
Cultivares (C) & 21 & $79.549 .824,3^{* *}$ \\
Interação (A x C) & 924 & $1.353 .194,9^{* *}$ \\
Resíduo & 1.890 & $301.876,9$ \\
\hline CV (\%) & \multicolumn{3}{l}{10,9} \\
\hline **Significativo a 1\% de probabilidade pelo teste $\mathrm{F}$.
\end{tabular}

condições $\left(b_{1}>1\right)$ e que a variedade Sertanejo mostrou ser menos exigente nessas mesmas condições. A estimativa de $b_{1}+b_{2}$, que avalia as respostas das cultivares nos ambientes favoráveis, evidenciou nesse grupo de materiais que apenas os híbridos AG 1051 e BR 3123 responderam à melhoria ambiental $\left(b_{1}+\right.$ $\left.\mathrm{b}_{2}>1\right)$. Todas as cultivares avaliadas apresentaram os desvios de regressão estatisticamente diferentes de zero, a $1 \%$ de probabilidade, o que indica comportamento imprevisível ou errático desses materiais nos ambientes considerados. Entretanto, as estimativas de $\mathrm{R}^{2}$ obtidas para as cultivares São Francisco, Sintético Dentado e Assum Preto foram iguais ou superiores a $80 \%$, o que não compromete seus graus de previsibilidade, segundo Cruz et al. (1989).

Relacionando-se a estabilidade das cultivares avaliadas no presente trabalho com as suas respectivas bases genéticas, percebe-se que todas essas cultivares apresentaram a mesma resposta à estabilidade $\left(\sigma_{\mathrm{di}} \neq 0\right)$, independentemente de suas bases genéticas (híbrido simples, híbrido duplo, híbrido triplo e variedade) (Tabela 4). Em trabalhos de competição de cultivares, em que se avaliam cultivares de diferentes bases genéticas, surge o questionamento sobre a maior ou menor estabilidade das cultivares em relação ao grupo a que pertencem (Ribeiro et al., 2000). Resultados de inúmeros trabalhos com a cultura do milho permitem inferir não haver relação fixa entre a homogeneidade ou heterogeneidade de determinado genótipo e sua estabilidade, sendo possível selecionar cultivares mais estáveis em qualquer grupo, quer sejam variedades, híbrido simples, híbrido triplo ou híbrido duplo (Gomes, 1990; Muniz, 1995; Carneiro, 1998; Carvalho et al., 2000a; Ribeiro et al., 2000), o que também foi constatado no presente trabalho.

A cultivar ideal preconizada pelo modelo bissegmentado ( $b_{0}$ alto, $b_{1}<1, b_{1}+b_{2}>1$ e desvios da regressão igual a zero) não foi encontrada no conjunto avaliado. Da mesma forma, não foi encontrada qualquer cultivar que atendesse a todos os requisitos necessários para adaptação aos ambientes desfavoráveis. Nesse caso, o material teria que apresentar estimativa $\hat{b}_{0}$ alta, $\hat{b}_{1}$ e $\hat{b}_{1}+\hat{b}_{2}<1$. Apesar disso, a variedade Sertanejo, por apresentar média alta, ser pouco exigente sob condições desfavoráveis $\left(\hat{b}_{1}<1\right)$ e apresentar estimativa de $b_{1}+b_{2}$ semelhante à unida- 
de, pode ser recomendada para as condições desfavoráveis. Apesar dos híbridos Cargill 333 B, AG 1051 e Zeneca 8501 serem exigentes nas condições desfavoráveis $\left(\hat{b}_{1}>1\right)$, apresentaram os melhores rendimentos médios de grãos nessas condições, o que sugere a possibilidade de também serem utilizados nesses ambientes. Da mesma forma, não foi encontrada qualquer cultivar que atendesse a todos os requisitos necessários de adaptação aos ambientes favoráveis, pois, teria que exibir estimativa de $b_{0}$ alta, $b_{1}+b_{2}>1 \mathrm{e}$ $\sigma_{\mathrm{di}}=0$. Mesmo assim, o híbrido AG 1051 atendeu a um maior número de requisitos para recomendação nessas condições (estimativa de $b_{0}$ alta e $b_{1}+b_{2}>1$ ). Os híbridos Cargill 333 B e Zeneca 8501, que apresentaram estimativas de $b_{0}$ alta, $b_{1}>1$ e $b_{1}+b_{2}=1$, também justificam as suas recomendações para as condições favoráveis. Os híbridos Colorado 32, BR 3123, AG 3041 e Agromen 3100, com estimativas de $b_{1}=1$, evidenciaram adaptabilidade geral, justificando suas recomendações para a Região Nordeste. Dentre estes, o BR 3123 destaca-se por responder à melhoria ambiental $\left(\hat{b}_{1}+\hat{b}_{2}>1\right)$, isto porque apresen- tou $\hat{b}_{2}>0$. No caso de adaptação ampla aos ambientes desfavoráveis $\left(\hat{b}_{1}=1\right)$, é a magnitude do $\hat{b}_{2}\left(\hat{b}_{2}<0\right.$ ou $\left.\hat{b}_{2}>0\right)$ que define a resposta do material nos ambientes favoráveis.

Considerando-se a média geral das variedades, populações e sintéticos $(4.583 \mathrm{~kg} / \mathrm{ha})$, a população CMS 50 e as variedades BR 106, Asa Branca, São Francisco, São Vicente, AL 25 e Sertanejo e os sintéticos Dentado e Duro revelaram boa adaptação no Nordeste brasileiro, concordando com os dados dos trabalhos de competição de cultivares nessa região (Cardoso et al., 2000; Carvalho et al., 2000a, 2000b). Nesse grupo, apenas a variedade AL 25 mostrou ser exigente nas condições desfavoráveis (estimativa de $b_{1}>1$ ), o que, associado ao bom rendimento apresentado, justifica sua recomendação para os ambientes melhorados. As variedades São Vicente, São Francisco e Asa Branca, em razão de seus altos rendimentos, com estimativas de $b_{1}=1$ e $b_{1}+b_{2}<1$, apresentaram tendência de adaptação aos ambientes desfavoráveis, sendo de grande importância para a região, especialmente, as variedades São Francisco e

Tabela 4. Estimativas das médias e dos parâmetros de adaptabilidade e estabilidade de 22 cultivares de milho em 45 ambientes do Nordeste brasileiro, segundo o método de Cruz et al. (1989), no triênio 1998/1999/2000.

\begin{tabular}{|c|c|c|c|c|c|c|c|c|}
\hline \multirow[t]{2}{*}{ Cultivares } & \multicolumn{3}{|c|}{ Médias de grãos (kg/ha) } & \multirow[t]{2}{*}{$b_{1}$} & \multirow[t]{2}{*}{$\mathrm{b}_{2}$} & \multirow[t]{2}{*}{$b_{1}+b_{2}$} & \multirow[t]{2}{*}{$\sigma_{\mathrm{di}}^{2}$} & \multirow[t]{2}{*}{$\mathrm{R}^{2}$} \\
\hline & Geral $^{(1)}$ & Desfavorável & Favorável & & & & & \\
\hline Cargill $333 \mathrm{~B}^{(2)}$ & 6.489 & 5.487 & 7.634 & $1,40 *$ & $-0,24 *$ & $1,14^{\mathrm{ns}}$ & $1.624 .977,8 * *$ & 78 \\
\hline $\mathrm{AG} 1051^{(3)}$ & 6.459 & 5.482 & 7.517 & $1,33^{*}$ & $-0,01^{\mathrm{ns}}$ & $1,34 * *$ & $1.921 .081,6^{* *}$ & 75 \\
\hline Zeneca $8501^{(4)}$ & 6.061 & 5.171 & 7.078 & $1,23 *$ & $-0,34 * *$ & $0,90^{\mathrm{ns}}$ & $2.038 .641,5^{* *}$ & 67 \\
\hline Colorado $32^{(4)}$ & 5.840 & 5.019 & 6.777 & $1,08^{\mathrm{ns}}$ & $-0,30 * *$ & $0,78^{*}$ & $1.789 .687,0^{* *}$ & 65 \\
\hline BR $3123^{(4)}$ & 5.666 & 4.812 & 6.641 & $1,10^{\mathrm{ns}}$ & $0,37 * *$ & $1,48 * *$ & $2.233 .195,6^{* *}$ & 68 \\
\hline AG $3010^{(3)}$ & 5.661 & 4.936 & 6.465 & $1,00^{\mathrm{ns}}$ & $-0,20^{\mathrm{ns}}$ & $0,80^{*}$ & $1.189 .967,2 * *$ & 71 \\
\hline Agromen $3100^{(3)}$ & 5.527 & 4.846 & 6.305 & $0,99^{\text {ns }}$ & $0,06^{\mathrm{ns}}$ & $1,06^{\mathrm{ns}}$ & $1.234 .133,0^{* *}$ & 73 \\
\hline Sertanejo $^{(5)}$ & 5.030 & 4.299 & 5.625 & $0,88^{\mathrm{ns}}$ & $0,01^{\mathrm{ns}}$ & $0,88^{\mathrm{ns}}$ & $2.019 .572,6^{* *}$ & 65 \\
\hline $\operatorname{AL~} 25^{(5)}$ & 4.993 & 4.109 & 6.001 & $1,24 * *$ & $-0,16^{\mathrm{ns}}$ & $1,08^{\mathrm{ns}}$ & $1.236 .137,6^{* *}$ & 78 \\
\hline São Vicente $e^{(5)}$ & 4.956 & 4.304 & 5.701 & $0,90^{\text {ns }}$ & $-0,01^{\mathrm{ns}}$ & $0,79 *$ & $1.453 .344,9 * *$ & 63 \\
\hline São Francisco ${ }^{(5)}$ & 4.917 & 4.217 & 5.720 & $0,97^{\mathrm{ns}}$ & $-0,31 * *$ & $0,65 * *$ & $652.781,4 * *$ & 80 \\
\hline Asa Branca ${ }^{(5)}$ & 4.813 & 4.173 & 5.543 & $0,89^{\text {ns }}$ & $-0,13 * *$ & $0,76^{* *}$ & $7.166 .647,2 * *$ & 77 \\
\hline Sintético Dentado ${ }^{(6)}$ & 4.763 & 4.026 & 5.604 & $1,09^{\mathrm{ns}}$ & $0,16^{\mathrm{ns}}$ & $1,26^{* *}$ & $644.610,0 * *$ & 87 \\
\hline Sintético Duro ${ }^{(6)}$ & 4.759 & 4.150 & 5.456 & $0,91^{\mathrm{ns}}$ & $0,02^{\mathrm{ns}}$ & $0,93^{\mathrm{ns}}$ & $777.454,8 * *$ & 78 \\
\hline BR $106^{(5)}$ & 4.686 & 3.993 & 5.477 & $0,92^{\mathrm{ns}}$ & $0,32 * *$ & $1,25 * *$ & $1.321 .770,4^{* *}$ & 71 \\
\hline CMS $50^{(7)}$ & 4.599 & 3.788 & 5.525 & $1,09^{\mathrm{ns}}$ & $0,01^{\mathrm{ns}}$ & $1,09^{\mathrm{ns}}$ & $1.179 .974,8^{* *}$ & 76 \\
\hline Cruzeta $^{(5)}$ & 4.502 & 4.009 & 5.064 & $0,79^{\text {ns }}$ & $-0,07^{\mathrm{ns}}$ & $0,71 * *$ & $852.052,8 * *$ & 69 \\
\hline CMS $453^{(7)}$ & 4.481 & 3.867 & 5.183 & $0,90^{\text {ns }}$ & $0,09^{\text {ns }}$ & $0,99^{\mathrm{ns}}$ & $781.725,6^{* *}$ & 78 \\
\hline $\operatorname{CMS} 59^{(7)}$ & 4.451 & 3.564 & 5.417 & $1,14^{*}$ & $0,12^{\mathrm{ns}}$ & $1,26^{*}$ & $1.760 .752,9 * *$ & 71 \\
\hline Assum Preto $^{(5)}$ & 4.301 & 3.672 & 5.020 & $0,87^{\text {ns }}$ & $0,17^{\mathrm{ns}}$ & $1,04^{\mathrm{ns}}$ & $636.915,1 * *$ & 81 \\
\hline CMS $35^{(7)}$ & 3.984 & 3.509 & 4.669 & $0,77^{* *}$ & $-0,12^{\text {ns }}$ & $0,65 * *$ & $1.212 .523,1^{* *}$ & 59 \\
\hline $\mathrm{CMS} 47^{(7)}$ & 3.505 & 3.130 & 3.932 & $0,43 * *$ & $0,66 * *$ & $1,09^{\text {ns }}$ & $1.063 .724,0 * *$ & 58 \\
\hline
\end{tabular}

${ }^{(1)}$ A média das cultivares foi $5.021 \mathrm{~kg} / \mathrm{ha} \mathrm{de} \mathrm{grãos} \mathrm{e} \mathrm{a} \mathrm{diferença} \mathrm{mínima} \mathrm{significativa} \mathrm{(DMS)} \mathrm{entre} \mathrm{as} \mathrm{médias} \mathrm{das} \mathrm{cultivares} \mathrm{foi} 572 \mathrm{~kg} / \mathrm{ha}$ de grãos. ${ }^{(2)} \mathrm{Híbrido}$ simples. ${ }^{(3)}$ Híbrido duplo. ${ }^{(4)}$ Híbrido triplo. ${ }^{(5)}$ Variedade. ${ }^{(6)}$ Sintético. ${ }^{(7)}$ População. ns Não-significativo. * e **Significativamente diferentes da unidade,

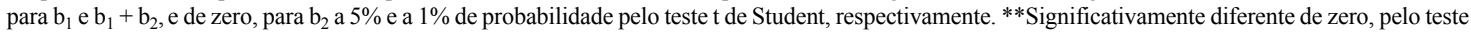
$\mathrm{F}$, para $\mathrm{s}_{\mathrm{di}}$. 
Asa Branca, de ciclo precoce. O Sintético Dentado e a variedade BR 106, com estimativas de $b_{1}=1 \mathrm{e}$ $\mathrm{b}_{1}+\mathrm{b}_{2}>1$, apresentaram tendência de adaptação aos ambientes favoráveis.

\section{Conclusões}

1. Os híbridos Cargill 333 B, AG 1051 e Zeneca 8501, pelos seus rendimentos nos ambientes favoráveis, e AG 1051, por ser também responsivo à melhoria ambiental, são indicados para agricultores do Nordeste brasileiro que possam investir em tecnologias de produção.

2. As variedades Sertanejo, São Vicente, São Francisco, Asa Branca e BR 106, de altos rendimentos médios e com tendências de adaptação aos ambientes desfavoráveis, são indicadas para os sistemas de produção dos pequenos e médios produtores rurais.

\section{Referências}

ARIAS, E. R. A. Adaptabilidade e estabilidade de cultivares de milho no Estado do Mato Grosso do Sul e avanço genético obtido no período de 1986/87 e 1993/94. 1995. 118 f. Tese (Doutorado em Genética e Melhoramento de Plantas) - Escola Superior de Agricultura de Lavras, Lavras, 1995.

CARDOSO, M. J.; CARVALHO, H. W. L. de; LEAL, M. de L. da S.; SANTOS, M. X. dos. Estabilidade de cultivares de milho no Estado do Piauí. Revista Científica Rural, Bagé, v. 5, n. 1, p. 62-67, 2000.

CARDOSO, M. J.; CARVALHO, H. W. L. de; PACHECO, C. A. P.; SANTOS, M. X. dos; LEAL, M. de L. da S. Adaptabilidade e estabilidade de cultivares de milho no Estado do Piauí no biênio 1993/94. Revista Científica Rural, Bagé, v. 2, n. 1, p. 35-44, 1997.

CARNEIRO, P. C. S. Novas metodologias de análises de adaptabilidade e estabilidade de comportamento. $168 \mathrm{f}$. Tese (Doutorado em Genética e Melhoramento de Plantas) - Universidade Federal de Viçosa, Viçosa, MG, 1998.

CARVALHO, H. W. L. de; LEAL, M. de L. da S.; ALBUQUERQUE, M. M. de; TABOSA, J. N. Estabilidade de cultivares de milho no Nordeste brasileiro no ano agrícola de 1996. Revista Científica Rural, Bagé, v. 3, n. 2, p. 20-26, 1998.
CARVALHO, H. W. L. de; LEAL, M. de L. da S.; SANTOS, M. X. dos; CARDOSO, M. J.; MONTEIRO, A. A. T. Adaptabilidade e estabilidade de variedades e híbridos de milho no Nordeste brasileiro. Revista Científica Rural, Bagé, v. 4, n. 1, p. 25-34, 1999a.

CARVALHO, H. W. L. de; LEAL, M. de L. da S.; SANTOS, M. X. dos; CARDOSO, M. J.; MONTEIRO, A. A. T.; TABOSA, J. N. Adaptabilidade e estabilidade de cultivares de milho no Nordeste brasileiro. Pesquisa Agropecuária Brasileira, Brasília, v. 35, n. 6, p. 11151123, jun. 2000a.

CARVALHO, H. W. L. de; LEAL, M. de L. da S.; SANTOS, M. X. dos; MONTEIRO, A. A. T.; CARDOSO, M. J.; CARVALHO, B. C. L. de. Estabilidade de cultivares de milho em três ecossistemas do Nordeste brasileiro. Pesquisa Agropecuária Brasileira, Brasília, v. 35 , n. 9 , p. $1773-1781$, set. 2000 b.

CARVALHO, H. W. L. de; MAGNAVACA, R.; LEAL, M. de L. da S. Estabilidade de cultivares de milho no Estado de Sergipe. Pesquisa Agropecuária Brasileira, Brasília, v. 27, n. 7, p. 1073-1082, jul. 1992.

CARVALHO, H. W. L. de; SANTOS, M. X. dos; LEAL, M. de L. da S.; PACHECO, C. A. P.; CARDOSO, M. J.; MONTEIRO, A. A. T. Adaptabilidade e estabilidade de produção de cultivares de milho no Nordeste brasileiro. Pesquisa Agropecuária Brasileira, Brasília, v. 34, n. 9 , p. 1581-1591, set. 1999b.

CARVALHO, H. W. L. de; SANTOS, M. X. dos; LEAL, M. de L. da S.; PACHECO, C. A. P.; TABOSA, J. N. Adaptabilidade e estabilidade de comportamento de cultivares de milho em treze ambientes nos Tabuleiros Costeiros do Nordeste brasileiro. Pesquisa Agropecuária Brasileira, Brasília, v. 34, n. 12, p. 2225-2234, dez. 1999c.

CRUZ, C. D.; TORRES, R. A. de; VENCOVSKY, R. An alternative approach to the stability analysis by Silva and Barreto. Revista Brasileira de Genética, Ribeirão Preto, v. 12, p. 567-580, 1989.

GAMA, E. E. G.; PARENTONI, S. N.; PACHECO C. A. P.; OLIVEIRA, A. C.; GUIMARÃES, P. E. de O.; SANTOS, M. X. dos. Estabilidade de produção de germoplasma de milho avaliado em diferentes regiões do Brasil. Pesquisa Agropecuária Brasileira, Brasília, v. 35, n. 6, p. 1143-1149, jun. 2000.

GOMES, L. S. Interação genótipos x épocas de plantio em milho (Zea mays $\mathbf{L}$.) em dois locais do Oeste do 
Paraná. 1990. 148 f. Dissertação (Mestrado em Genética e Melhoramento de Plantas) - Escola Superior de Agricultura Luiz de Queiroz, Piracicaba, 1990.

LEMOS, M. A. Variabilidade fenotípica em híbridos simples, variedades e compostos de milho. 1976. $62 \mathrm{f}$. Dissertação (Mestrado em Genética e Melhoramento de Plantas) - Escola Superior de Agricultura Luiz de Queiroz, Piracicaba, 1976.

MARIOTTI, I. A.; OYARZABAL, E. S.; OSA, J. M.; BULACIO, A. N. R.; ALMADA, G. H. Análisis de estabilidad y adaptabilidad de genotipos de caña de azúcar. I. Interacciones dentro de una localidad experimental. Revista Agronómica del Nordeste Argentino, Tucumán, v. 13, n. 14, p. 105-127, 1976.

MUNIZ, J. A. Avaliação da estabilidade de cultivares de milho em diferentes níveis de adubação e locais da região de Lavras, MG. 1995. 60 f. Dissertação (Mestrado em Genética e Melhoramento de Plantas) - Escola Superior de Agricultura de Lavras, Lavras, 1995.

NASPOLINI FILHO, W. Variabilidade fenotípica e estabilidade em híbridos simples, híbridos duplos, variedades e compostos de milho. 1976. $68 \mathrm{f}$. Dissertação (Mestrado em Genética e Melhoramento de Plantas) Escola Superior de Agricultura Luiz de Queiroz, Piracicaba, 1976.

PIMENTEL-GOMES, F. Curso de estatística experimental. 11. ed. São Paulo: Nobel, 1985. 450 p.
RAMALHO, M. A. P.; SANTOS, J. B. dos; ZIMMERMANN, M. J. de O. Interação dos genótipos x ambientes. In: RAMALHO, M. A. P.; SANTOS, J. B. dos; ZIMMERMANN, M. J. de O. Genética quantitativa em plantas autógamas: aplicação no melhoramento do feijoeiro. Goiânia, Editora da UFG, 1993.p. 131-169. (Publicação, 120).

RIBEIRO, P. H. E.; RAMALHO, M. A. P.; FERREIRA, D. F. Adaptabilidade e estabilidade de cultivares de milho avaliadas em diferentes condições ambientais. Pesquisa Agropecuária Brasileira, Brasília, v. 35, n. 11, p. 22132222, nov. 2000.

RUSCHEL, R. Interação genótipo $\mathbf{x}$ localidade na região Centro Sul em milho (Zea mays L.). 1968. $60 \mathrm{f}$. Dissertação (Mestrado em Genética e Melhoramento de Plantas) - Escola Superior de Agricultura Luiz de Queiroz, Piracicaba, 1968.

SAS INSTITUTE (Cary, Estados Unidos). SAS/STAT user's guide: version 6.4. Cary, 1996. v. 1.

SCAPIM, C. A.; CARVALHO, C. G. P. de; CRUZ, C. D. Uma proposta de classificação dos coeficientes de variação para a cultura do milho. Pesquisa Agropecuária Brasileira, Brasília, v. 30, n. 5, p. 683-686, maio 1995.

SILVA, F. B. R. de; RICHE, G. R.; TORNGAU, J. P.; SOUSA NETO, N. C. de; BRITO, L. T. de L.; CORREIA, R. C.; CAVALCANTI, A. C.; SILVA, F. H. B. B. da; SILVA, A. D. da; ARAÚJO FILHO, J. C. de; LEITE, A. P. Zoneamento ecológico do Nordeste: diagnóstico do quadro natural e agrossocioeconômico. Petrolina: EmbrapaCPATSA/Embrapa-CNPS, 1993. v. 1. 